trong nhóm nghiên cứu ở mức trung bình với5,99 $\pm 1,98$ điểm, Trong đó tỷ lệ sinh viên có kiến thức trung bình chiếm $58,2 \%$ và kiến thức kém chiếm $18,7 \%$. Kết quả nghiên cứu của chúng tôi cũng phù hợp với nghiên cứu của Endalew, G.S. (2014) phần lớn (63\%) sinh viên có kiến thức không đây đủ về PEP của HIV, 91(49.2\%) sinh viên điêuu dưỡng báo cáo rằng đã từng nghe về PEP [7].

4.8. Kiến thức chung vê dự phòng phơi nhiễm. Nhìn chung kiến thức của sinh viên về dư phòng phơi nhiểm ở mức đô trung bình. Kết quả bảng 3.6 với điểm trung bình chung là 7,71 $\pm 0,71$ điểm, trong đó tỷ lệ sinh viên có kiến thức ở mức trung bình chiếm $63,7 \%$, chỉ có $36,3 \%$ là mức tốt.Kết quả nghiên cứu của chúng tôi tương tự môt số nghiên cứu cho thấy điểm kiến thức của sinh viên điều dưỡng về các biện pháp phòng ngừa tổn thương do vật sắc nhọn cũng ở mức trung bình[7],[8].

\section{KẾT LUÂ̂N}

Kiến thức chung của sinh viên điều dưỡng năm cuối về phòng ngừa phơi nhiễm với máu, dịch cơ thể ở mức trung bình với điểm trung bình chung đạt 7,71 $\pm 0,71$ (thang điểm 10). Trong có tỷ lệ sinh viên có kiến thức mức trung bình chiếm $63,7 \%$ và chỉ có $36,3 \%$ sinh viên có kiến thức tốt.

Các lĩnh vực sinh viên có kiến thức tốt là: Kiến thức về khái niệm, phương thức phơi nhiễm; chăm sóc sức khỏe nghề nghiệp cơ bản; các biện pháp phòng ngừa; báo cáo và lập biên bản với điểm số trung bình lần lượt là 8,38 điểm; 8,64 điểm; 8,36 điểm; 9,38 điểm và 9,14 theo thang điểm 10 .
Các lĩnh lực sinh viên có kiến thức chưa tốt (ở mức trung bình) là: Kiến thức về sơ cứu tại chồ; đánh giá nguồn gây phơi nhiễm với điểm số trung bình lần lượt là 7,84 điểm; 7,07 điểm;

\section{TÀI LIÊU THAM KHẢO}

1. Bộ $\mathbf{Y}$ tế (2012). Hướng dẫn tiêm an toàn trong các cơ sở khám, chữa bênh. Ban hành kèm theo Quyết định số 3671/QĐ-BYT của Bộ trưởng Bộ Y tế về việc phê duyệt các Hướng dẫn kiểm soát nhiếm khuân.

2. Bộ Y tế (2012).Tài liệu đào tạo phòng và kiểm soát nhiễm khuân, Nhà xuất bản y học, Hà Nội.

3. Lê Thị Anh Thư (2010). Hiệu quả của chương trình phòng ngừa phơi nhiễm do nghề nghiệp tại Bệnh viện Chợ Rẫy, Tap chí Y học Thành Phố Hồ Chí Minh, 14(2), tr. 429-435.

4. Ah Al-Hazmi (2015). Knowledge, attitudes, and practice of medical students regarding occupational risks of hepatitis B virus in college of medicine, aljouf university, Annals of medical and health sciences research, 5(1), pp. 13-19.

5. M.I. Alhowaish and et al. (2017). Knowledge, attitudes and practices toward prevention of hepatitis $B$ virus infection among medical students at Northern Border University, Arar, Kingdom of Saud Arabia.Electronic physician, 9(9), pp. 5388-5394.

6. A. P. Anjana, Gisha Joseph and Revathy Valsan (2018).Assessment of Knowledge Regarding Post exposure Prophylaxis Following Needle Stick Injury among b. Sc. Nursing Students.Indian Journal of Public Health Research \& Development, 9, p. 6.

7. G.S. Endalew (2014). Assessment of Level of Knowledge and Practice of Nursing and Midwifery Students on HIV Post Exposure Prophylaxis in Hawassa University, Ethiopia.Journal of HIV for Clinical and Scientific Research, 1(1), pp. 1-6.

8. Dixit Sanjay and et al. (2010). Impact of Educational Intervention Measures on Knowledge regarding HIV/ Occupational Exposure and Post Exposure Prophylaxis among Final Year Nursing Students of a Tertiary Care Hospital in Central India.Online Journal of Health \& Allied Sciences, 8.

\title{
ẢNH HƯỞNG CỦA NHAI KEO CAO SU XYLITOL ĐẾN LƯU LƯỢNG VÀ pH NƯỚC BỌT
}

\section{TÓM TẮT}

Nghiên cứu can thiệp không đối chứng được thức hiện trên 43 sinh viên trường Đại học Y Dược Thái Nguyên được thực hiện để đánh giá ảnh hưởng của nhai kẹo cao su xylitol đến lưu lượng và $\mathrm{pH}$ nước bọt.

*Trường Đại học Y Dược Thái Nguyên

Chịu trách nhiệm chính: Lê Thị Thu Hằng

Email: hang.thithule@gmail.com

Ngày nhận bài: 16/3/2021

Ngày phản biện khoa học: 13/4/2021

Ngày duyệt bài: 7/5/2021

\section{Lê Thị Thu Hằng*, Trần Phương Nga*}

Các mẫu nước bọt được lấy ở trạng thái nghi, sau khi nhai xylitol và đo lưu lượng theo quy trình chuẩn, $\mathrm{pH}$ được xác định bằng máy đo $\mathrm{pH}$ Hanna. Kết quả cho thấy, $86 \%$ mẫu nước bọt ở trạng thái nghi có lưu lượng ở mức bình thường, $100 \%$ mấu nước bọt ở trạng thái kích thích có lưu lượng nước bọt bình thường. Hơn nữa, lưu lượng nước bọt ở trạng thái nghi $(0,47 \pm 0,24 \mathrm{ml} /$ phút) thấp hơn rõ so với lưu lượng nước bọt $(2,84 \pm 0,9 \mathrm{ml} /$ phút) sau nhai keo cao su xylitol $(p<0,001)$. PH nước bọt ở trạng thái nghì $(6,85 \pm 0,56)$ thấp hơn rõ so với sau khi nhai kẹo xylitol $(7,09 \pm 0,34)$ với $p=0,011$. Kết luận: Nhai kẹo xylitol có tác dụng làm tăng lưu lượng và pH nước bọt. 

xylitol

Tứ khóa: Nước bọt, pH, lưu lượng, kẹo cao su

\section{SUMMARY}

AFFECTING OF XILITOL CHEWING GUM ON SALIVARY FLOW RATE AND pH

A quasi- experimental study was conducted in 43 students of Thai Nguyen University of Medicine and Pharmacy in order to evaluate the changes in salivary flow rate and $\mathrm{pH}$ before and after chewing xylitol gum. Saliva samples were collected and measured with standard procedures, salivary $\mathrm{pH}$ before and after chewing xylitol gum was determined using Hanna $\mathrm{pH}$ meter. The results showed that $86 \%$ students were normal flow rate in unstimulated saliva and $100 \%$ students were normal flow rate in stimulated saliva. Unstimulated salivary flow rate $(0,47$ $\pm 0,24 \mathrm{ml} / \mathrm{min}$ ) was statistically significant lower than stimulated $(2,84 \pm 0,9 \mathrm{ml} / \mathrm{min})$ by using xylitol chewing gum $(\mathrm{p}<0,001) . \mathrm{pH}$ of unstimulated saliva $(6,85 \pm 0,56)$ was statistically significant lower than that of stimulated saliva $(7,09 \pm 0,34)$ with $p=0,011$. Conclusion: Using xylitol chewing gum may increase the flow rate and $\mathrm{pH}$ of saliva.

Keywords: Salivary, $\mathrm{pH}$, flow rate, xylitol

\section{I. ĐĂT VẤN ĐỀ}

Bệnh sâu răng là một bệnh rất phổ biến với tỉ lệ mắc cao, bệnh có thể gặp ở mọi lứa tuổi, mọi giới và mọi vùng địa lý [1]. Mặc dù nhiêu biện pháp dự phòng sầu răng đã được áp dụng nhưng tỉ lệ bệnh vẫn còn cao và vẫn luôn là một trong những mối quan tâm hàng đầu của ngành y tế trên thế giới cũng như ở Việt Nam. Mặt khác, trong những năm gần đây, nước bọt đã được một số nghiên cứu công bố với vai trò quan trọng trong bảo vệ răng. Số lượng và chất lượng nước bọt đóng vai trò quan trọng trong cân bằng pH khoang miênng (Leone CW, 2001) [1]. Những thay đổi cụ thể, chẳng hạn như tăng $\mathrm{pH}$, khả năng đệm và tốc độ dòng chảy có thể góp phần làm giảm tính nhạy cảm với sâu răng (Hegde MN, 2019) [2]. Giảm tốc độ dòng chảy nước bọt và giảm hệ thống đệm có thể là nguy cơ gây sâu răng và viêm niêm mạc miệng nghiêm trọng.

Một số nghiên cứu đã đề xuất tác dụng của việc nhai kẹo cao su xylitol trong phòng và điều trị bệnh sâu răng theo hướng Xylitol có một số tác động lên tính chất nước bọt theo chiêu hướng có lợi cho răng [3]. Đây là biện pháp có tính khả thi cao có thể lan tỏa trong cộng đồng nếu hiệu quả được chứng minh Tuy nhiên bằng chứng khoa học về tác động của việc nhai kẹo cao su xylitol đến lưu lượng và $\mathrm{pH}$ nước bọt còn chưa đầy đủ. Vì vậy nghiên cứu này được thực hiện với mục tiêu đánh giá ảnh hưởng của nhai kẹo cao su xylitol đên lưu lượng và pH nước bọt.
II. ĐỐI TƯỚNG VÀ PHƯƠ'NG PHÁP NGHIÊN CỨU

2.1. Đối tượng nghiên cứu: Sinh viên Răng Hàm Mặt, Trường Đại học Y Dược Thái Nguyên

2.2. Địa điểm và thời gian nghiên cứu: Từ 3/2020 đến 4/2021 tại Trường Đại học $Y$ Dược Thái Nguyên

\subsection{Phương pháp nghiên cứu:}

- Thiết kế nghiên cứu: Nghiên cứu can thiệp không đối chứng

- Chọn mẫu: Sinh viên đồng ý tham gia nghiên cứu, có chỉ số DMFT < 3 (theo tiêu chuẩn của WHO) và OHI-S < 1,2 được lựa chọn vào nghiên cứu. Những người đang mắc các bệnh nhiếm trùng cấp tính hoặc các bệnh mạn tính có liên quan đến sức khỏe toàn thân hoặc tuyến nước bọt, đã và đang sử dụng các loại thuốc kháng sinh, thuốc giao cảm hoặc thuốc có tác dụng phụ làm tăng giảm tiết nước bọt hoăcc thay đổi pH nước bọt trong 2 tháng; điều trị chiếu xạ vùng đầu mặt cổ trong 3 tháng gần thời điểm lấy mẫu bị loại trừ. Trong tổng sổ 56 sinh viên đồng ý tham gia nghiên cứu có 47 sinh viên đáp ứng đủ tiêu chuẩn và được lựa chọn. Trong 47 sinh viên tham gia lấy mẫu có 44 mẫu đạt và 3 mẫu không đạt do lượng nước bọt ở trạng thái nghỉ ít hơn $0,2 \mathrm{ml}$ là lượng nước bọt tối thiểu để máy đo $\mathrm{pH}$ có thể đo được kết quả chính xác.

2.4. Chỉ tiêu nghiên cứu: Các thông tin chung của đối tượng nghiên cứu được thu thập qua phỏng vấn trực tiếp bằng phiếu được thiết kế sẳn. Mẫu nước bọt ở trạng thái nghỉ và sau nhai kẹo cao su xylitol được thu thập theo qui trình chuẩn. Đối tượng được lựa chọn vào nghiên cứu được làm sạch cao răng trước ngày lấy mẫu nước bọt. Trong ngày thực hiện lây mẫu, bệnh nhân được yêu cầu không sử dụng các loại đồ ăn trước thời điểm lấy mẩu 8 tiểng. Tất cả mẫu đều được lấy vào buổi sáng để đảm bảo yêu cầu và giảm thiểu sai số. Lưu lương nước bọt ở trạng thái nghỉ và sau nhai kẹo cao su xylitol được xác định bằng milliliter/phút có sử dụng cốc chia vạch, đồng hồ bấm giờ. pH nước bọt ở trạng thái nghỉ và sau nhai kẹo xylitol được xác định bằng Hanna $\mathrm{pH}$ meter.

2.5. Kỹ thuật thu thập số liêu: Phỏng vân, khám răng miệng, thu thập mẫu nước bọt được thực hiện bởi 2 bác sĩ Răng Hàm Mặt và 1 kỹ thuạât viên đã được tập huấn. Tất cả các thông in trên được thu thập và điền vào phiếu thiết kế sẵn.

2.6. Xử lý số liệu: Số liệu được xử lý bằng các thuật toán thống kê y học. Giá trị trung bình, tỉ lệ phần trăm, t-test đã được sử dụng. 
2.7. Đạo đức nghiên cứu: Nghiên cứu đã được Hội đồng Đạo đức nghiên cứu y sinh học trường Đại học $Y$ Dược Thái Nguyên phê duyệt (số 239/ĐHYD-HĐĐĐ )

\section{KẾT QUẢ NGHIÊN CỨU}

Trong tổng số 43 sinh viên tham gia nghiên cứu, tỷ lệ nam, nữ lần lượt là $30,2 \%$ và $69,8 \%$, phân bố không đồng đều giữa các dân tộc với dân tộc Kinh chiếm tỷ lệ cao nhất $(69,8 \%)$ và dân tộc Sán Dìu, Cao Lan thấp nhất $(4,3 \%)$.

Bảng 1. Đặc điểm đối tượng nghiên cứu

\begin{tabular}{|c|c|c|}
\hline Đăc điếm & $n$ & $\%$ \\
\hline Giới: & 13 & 30,2 \\
\hline Nữ & 30 & 69,8 \\
\hline Dân tộc: Kinh & 30 & 69,8 \\
\hline Tày & 4 & 9,3 \\
\hline Mường & 2 & 4,7 \\
\hline Nùng & 3 & 7,0 \\
\hline Sán dìu & 2 & 4,3 \\
\hline Cao lan & 2 & 4,3 \\
\hline
\end{tabular}

Lưu lượng nước bọt ban đâu của 43 sinh viên có $86 \%$ đạt giới hạn bình thường. Sau khi nhai kẹo cao su Xylitol, 100\% sinh viên có lưu lượng nước bot trong giới hạn bình thường.

Bảng 2. Lưu lượng nước bọt ở trạng thái nghi và sau nhai keo cao su xylitol

\begin{tabular}{|c|c|c|c|}
\hline & $\begin{array}{c}\text { Rất } \\
\text { thấp } \\
\text { n(\%) }\end{array}$ & $\begin{array}{c}\text { Thấp } \\
\mathbf{n ( \% )}\end{array}$ & $\begin{array}{c}\text { Bình } \\
\text { thường } \\
\mathbf{n ( \% )}\end{array}$ \\
\hline Trạng thái nghỉ & 0 & $6(14 \%)$ & $37(86 \%)$ \\
\hline $\begin{array}{c}\text { Trạng thái kích } \\
\text { thích }\end{array}$ & 0 & 0 & $43(100 \%)$ \\
\hline
\end{tabular}

Lưu lượng nước bọt ở trạng thái nghỉ $(0,47 \pm$ $0,24 \mathrm{ml} /$ phút) thấp hơn rõ so với lưu lượng nước bọt $(2,84 \pm 0,9 \mathrm{ml} /$ phút) sau nhai kẹo cao su xylitol $(p<0,001)$.

Bảng 3. So sánh lưu lượng nước bọt ở trạng thái nghi và sau khi nhai kẹo Xylitol

\begin{tabular}{|c|c|c|c|c|}
\hline & $\mathbf{X} \pm$ & $\mathbf{S D}$ & $\mathbf{P}$ & $\mathbf{9 5 \% C I}$ \\
\hline Trạng thái nghi & $0.47 \pm$ & 0.24 & $<$ & $2.11-$ \\
\cline { 1 - 3 } $\begin{array}{c}\text { Trạng thái kích } \\
\text { thích }\end{array}$ & $2.84 \pm$ & 0.90 & 0.001 & 2.64 \\
\hline
\end{tabular}

So sánh pH nước bọt ở 2 trạng thái cho thấy pH ở trạng thái nghỉ $(6,85 \pm 0,56)$ thấp hơn rõ so với pH nước bọt sau khi nhai kẹo xylitol $(7,09$ $\pm 0,34)$ với $p=0,011$.

Bảng 4. So sánh $p H$ nước bọt ở trạng thái nghi và sau khi nhai kẹo Xylitol

\begin{tabular}{|c|c|c|c|c|}
\hline & $\mathbf{X} \pm$ & SD & $\mathbf{p}$ & $\begin{array}{c}\mathbf{9 5 \%} \\
\text { CI }\end{array}$ \\
\hline $\begin{array}{c}\text { Trạng thái } \\
\text { nghỉ }\end{array}$ & $6.85 \pm$ & 0.56 & 0.011 & $\begin{array}{c}0.06- \\
0.42\end{array}$ \\
\hline $\begin{array}{c}\text { Trang thái } \\
\text { kích thích }\end{array}$ & $7.09 \pm$ & 0.34 & & \\
\hline
\end{tabular}

\section{BÀN LUÂN}

Từ kết quả của nghiên cứu cho thây trung bình lưu lượng nước bọt ở trạng thái nghỉ thấp hơn đáng kể ở trạng thái kích thích. Sự khác biệt về độ tuổi đối tượng, quốc gia khác nhau, chủng tộc khác nhau và chất kích thích cũng tạo ra sự thay đổi về lưu lượng nước bọt. Kết quả nghiên cứu của Ralph M. Duckworth, S. Jones (2015), sử dụng surcrose lưu lượng tăng từ $0,76 \pm 0,26 \mathrm{~g} /$ phút lên $1,14 \pm 0,40 \mathrm{~g} /$ phút, nhưng sử dụng $\mathrm{NaCl}$ thì lưu lượng tăng từ $0,91 \pm 0,46$ lên 1,78 $\pm 0,53 \mathrm{~g} /$ phút [4]. Còn một số nghiên cứu khác như của Yas (2009) ở độ tuổi 30-40 và 5565, quốc gia Iraq cho lưu lượng trạng thái nghỉ lân lượt là $0,46 \pm 0,21$ và $0,38 \pm 0,24$ [5]. Một lý do khác gây ra sự khác biệt giữa lưu lượng nước bọt giữa các nghiên cứu khác nhau là giới tính, nhiều nghiên cứu chỉ ra rằng nữa có lưu lượng thấp hơn đáng kể so với nam ở cả 2 trạng thái nghỉ hay kích thích vì vậy nên tỷ lệ giới tính trong nhóm đối tượng nghiên cứu cũng tạo ra sự khác biệt này[6].

Sự thay đổi lưu lượng nước bọt trước và sau khi sử dụng xylitol có ý nghĩa thống kê $(p<0,05)$ cho thấy ảnh hưởng tích cực của kẹo cao su đối với khả năng tiết nước bọt. Nghiền cứu của chúng tôi ủng hộ cho kết luận đưa xylitol trở thành chiến lược phòng ngừa trong vệ sinh răng miệng hàng ngày ngày theo Autio JT và cộng sự, 2001[7]. Như chúng ta đã biết, lưu lượng nước bọt lớn giúp tăng khả năng làm sạch của nước bọt, đào thải mầm bệnh và từ đó làm giảm nguy cơ sâu răng. Vì vậy, kết quả tăng lưu lượng nước bọt đáng kể sau khi dùng xylitol cân được quan tâm hơn trong việc xây dựng biện pháp phòng ngừa sâu răng đặc biệt là sâu răng học đường.

$\mathrm{pH}$ nước bọt qua nghiên cứu của $\mathrm{C}$. FenollPalomares và cộng sự không có sự khác biệt giữa nam và nữ [8], với nam là $6,8400 \pm 0,3199$ và nữ là $6,7661 \pm 0,2686$, chỉ số trung bình tương tự như kết quả của nghiên cứu của chúng tôi khi ở trạng thái nghỉ. $\mathrm{pH}$ trung bình ở trang thái nghỉ thấp hơn đáng kể hay có tính axit hơn $\mathrm{pH}$ ở trạng thái kích thích. pH nước bọt có vai trò quan trọng vì ảnh hưởng đến phản ứng hóa học trong môi trường miệng. Cán cân acid - base bị lệch về hướng acid sẽ làm thuận lợi cho quy trình hủy khoáng, $\mathrm{pH}<5$ bắt đầu xảy ra sự hủy hoáng và quá trình ngược lại, sẽ xảy ra quy trình tái khoáng nhờ các ion trong nước bọt. Sau khi dùng xylitol thì lượng nước bọt tăng, điều này cũng tái tạo lại độ pH trong miệng, giúp tăng $\mathrm{pH}$, tái tạo men răng. Điều chỉnh độ $\mathrm{pH}$ trong 
miệng vai trò do hệ thống đệm của nước bọt. Xylitol bản thân nó không cung cấp thêm các thành phần của hệ đệm (bicarbonate, phosphate...) mà nó kích thích các tuyến nước bọt tiết ra nhiều hơn để trung hòa axid trong miệng, tạo ra sản phẩm là CO2 thoát ra khỏi khoang miệng và kết quả là loại bỏ axid, chống lại sâu răng (Ericsson, 2007). Vai trò của pH liên quan đến chỉ số sâu mất trám thể hiện rõ rệt qua nghiên cứu của Ahlam T. Al-Mashhadani và cộng sự (2005) với kết quả pH từ 7,7-8,1 có chỉ số DMFS thấp hơn đáng kể so với nhóm có pH từ 6,9-7,3. Nghiên cứu của $M$ Ribelles Llop và cộng sự (2010) khẳng định thêm tác dụng nhai kẹo xylitol giúp kích thích dòng chảy, phục hồi $\mathrm{pH}$ và giảm mức S.mutan trong nước bọt. Vì vậy, ảnh hưởng của xylitol lên pH nước bọt với tác động tăng $\mathrm{pH}$ đáng kể có vai trò quan trọng trong phòng ngừa sâu răng.

\section{KẾT LUÂ̂N}

Sử dụng kẹo xylitol có hiệu quả tăng lưu lượng nước bọt và tăng pH nước bott, tuy nhiên, cũng cần đánh giá tại nhiều thời điểm hơn để xem khả năng duy trì hiệu quả của phương pháp này.
TÀI LIỆU THAM KHẢO

1. Leone CW, Oppenheim FG. Physical and chemical aspects of saliva as indicators of risk for dental caries in humans. J Dent Educ. 2001; 65: 1054-1062.

2. Hegde $\mathbf{M N}$, Attavar SH, Shetty $\mathbf{N}$ et al. Saliva as a biomarker for dental caries: A systematic review. J Conserv Dent. 2019; 22(1): 2-6.

3. Sok JJ, Jaspreet B,Paul I et al. Oral and Systemic Effects of Xylitol Consumption. Caries Res. 2019; 9(53): 491-501.

4. Ralph M. Duckworth, S. Jones. On the relationship between the rate of salivary flow and salivary fluoride clearance. Caries Res. 2015; 49: 141-146.

5. Israa Mohammed Dawood, Sulafa K. ElSamarra. Saliva and Oral Health. International Journal of Advanced Research in Biological Science. 2018; 5(7): 1-45.

6. Sawair F., Kosti O., Getting S., and Renshaw D. Saliva: Physiology and diagnostic potential in health and disease. Scientific World Jornal, 2010; 10: 11-12

7. Autio JT, Courts FJ. Acceptance of the xylitol chewing gum regimen by preschool children and teachers in a Head Start program: a pilot study. Pediatric Dentistry. 2001; 23(1): 71-74.

8. C Fenoll - Palomares at al. Unstimulated salivary flow rate, $\mathrm{pH}$ and buffer capacity of saliva in healthy volunteers. Revista espanola de enfermedades digestivas: organo oficial de la Sociedad Espanola de Patologia Digestiva. 2004; 96(11):773-83

\title{
KHẢO SÁT TÌNH HÌNH SỬ DUNG ĐIÊN THOAI THÔNG MINH Ở SINH VIÊN ĐAI HỌC TRÊN ĐİA BÀN HÀ NộI BẰNG THANG ĐIỂM ĐÁNH GIÁ NGHIỆN ĐIỆN THOẠI THÔNG MINH PHIÊN BẢN RÚT GỌN
}

\author{
Đinh Trọng Hà*, Quản Minh Anh*, \\ Nguyễn Thị Hoa*, Nguyễn Lê Chiến* Trần Hải Anh*
}

\section{TÓM TẮT}

Mục tiêu: Đánh giá một số đặc điểm xã hội hoc về sử dụng điện thoại thông minh ở những sinh viển đại học trên địa bàn Hà Nội. Đối tượng và phương phã́p: Nghiên cứu mô tả cắt ngang được tiến hành ngấu nhiên trên 1314 sinh viên năm 2-4 tại 36 trường đại học trên đia bàn thành phố Hà Nội. Các đối tượng được hướng dẫn trả lời trực tuyến bộ câu hỏi sử dụng thang đo nghiện điện thoai thông minh phiên bản rút gọn trên Google Form. Kểt quả: Trong các đối tượng tham gia, nữ giới chiếm ưu thế $(71,61 \%)$ và sinh viên tuổi từ 18-21 chiếm phân lớn. Tỳ lệ sinh viên nghiện sử dung điên thoai thông minh là $55,56 \%$, trong đó tuổi 18-20 chiếm tỷ lệ cao hơn các lứa tuổi khác. Bắt

*Hoc viện Quân y

Chịu trách nhiệm chính: Trân Hải Anh

Email: anhhtr@yahoo.com

Ngày nhận bài: $15 / 3 / 202$

Ngày phản biên khoa hoc: 12/4/2021

Ngày duyệt bài: 7/5/2021 đâu sử dụng điện thoại thông minh của sinh viên tập trung chủ yếu ở tuổi 12-18. Phần lớn sinh viên trong nghiên cứu này sử dụng ứng dụng Facebook và Facebook Messenger trên điện thoại thông minh. Sinh viên nghiện điện thoại thông minh có tần suất tập thể dục và tham gia làm thêm thấp hơn so với nhóm không nghiện. Kết luận: Tỷ lệ sinh viên trên địa bàn Hà Nô̂i nghiện sử dung điên thoai thông minh cao và những khác biệt giữa sinh viển nghiện và không nghiên điên thoại thông minh về các yếu tố xã hội hoc là một thực trạng đáng lo ngại, đó cũng là dấu hiệu cảnh báo cần thiết để tìm kiếm các biện pháp nghiển cứu và can thiệp ở cấp độ rộng hơn cho hiện trạng nghiên này.

Từ khóa: Điện thoại thông minh, nghiện điện thoại thông minh, sinh viển.

\section{SUMMARY \\ EVALUATION OF SMARTPHONE USAGE AMONG STUDENTS IN HANOI USING SMARTPHONE ADDICTION SCALE-SHORT VERSION (SAS-SV)}

